\title{
Neuroticism as a Determinant of Job Satisfaction among Bank Employees
}

\section{Clifford Kendrick Hlatywayo}

University of Fort Hare, Alice, South Africa vakendie@gmail.com

\section{Tatenda Shaleen Mhlanga}

University of Fort Hare, Alice, South Africa tatenda.mhlanga@gmail.com

\section{Tawanda Zingwe}

University of Fort Hare, Alice, South Africa tzingwe@gmail.com

\section{Doi:10.5901/mjss.2013.v4n13p549}

\section{Abstract}

The study explored the relationship between neuroticism and Job satisfaction. Employees with low levels of neuroticism experience higher levels of job satisfaction. The banking environment requires employees with low levels of neuroticism due to the nature of services they offer. A quantitative technique was adopted, to determine the relationship between neuroticism and job satisfaction SAS 9.1, Pearson's Correlation Coefficient, ANOVA and Waller- Duncan K-ratio T-Test and T-Test were used. Findings indicated employees had low level of criticism and were satisfied with their jobs. However the level of neuroticism was influenced by demographic variable (age, race, and bank) but this did not have any significant impact on overall job satisfaction. The findings will aid management institutions in selecting, and retaining employees as higher job satisfaction is linked to higher levels of productivity, effectiveness and commitment

Keywords: neuroticism, bank employees, job satisfaction

\section{Introduction}

Buitendach \& de Witte (2005) proffer the view that job satisfaction relates to an individual's perceptions and evaluations of a job, and this perception is in turn influenced by their circumstances, including needs, values and expectations. Individuals therefore evaluate their jobs on the basis of factors which they regard as being important to them (Sempane et al., 2002).

The majority of job satisfaction and motivation research literature is concerned with organisational or situational predictors (such as pay and supervision) (Locke, 1976) while neglecting individual differences (Staw \& Ross, 1985). Job satisfaction influences an organization's well-being with regard to job productivity, employee turnover, absenteeism and life satisfaction (Spector, 2008).

Camgoz and Karapinar (2011) highlighted the importance of testing the mediated relationship between personality and job satisfaction, personality is connected with behaviour (Barrick \& Mount, 2005). Scholars in support of this notion argue that good service often comes from employees who possess a good personality and emotional intelligence.

The study will look into individual differences, which is the personality trait of neuroticism and how it affects job satisfaction. It is crucial to understand how personality traits affect job satisfaction to improve the selection, recruitment and placing processes in organizations. It also helps individuals to choose their field of study with an understanding of their personality to avoid dissatisfaction as it impacts negatively on their working lives. This comes from the assumption that when an individual is in a job situation that suits their personality they are more satisfied than individuals with a contrasting personality. However Cohrs, Abele \& Dette, (2006) in Camgoz and Karapinar (2011) argue that job satisfaction is influenced by some factors other than individual traits. 


\section{Neuroticism and Job Satisfaction}

Neuroticism is also referred to as emotional stability (Goldberg, 1992). Neuroticism is known characterised by upsetability which is the polar opposite of emotional stability. Anxiety, Hostility, Depression, Self-Consciousness, Impulsiveness and Vulnerability to Stress are the constructs that define neuroticism.

Emotional stability is the low score of neuroticism (Terracciano, Löckenhoff, Zonderman, Ferrucci \& Costa 2008; Widiger \& Trull, 1992; Costa \& McCrae, 1980). Watson \& Hubbard, 1996; Judge \& Cable, 1997; Judge \& llies, 2000 showed that neuroticism is negatively correlated with job satisfaction while emotional stability is positively correlated to job satisfaction. This was attributed to neurotic individuals as they are usually anxious, moody and lack self-confidence and dwell in negative emotions, which make them not enjoy the work they do. Emotionally stable individuals are able to control their emotions; hence, it's positively correlation to job satisfaction. Thus, neurotic individuals usually are less satisfied with their jobs than those who are emotionally stable.

Employees with high neuroticism scores tend to be less satisfied with the amount of work, their co-workers and their pay, while employees with high psychoticism (tough-minded) tend to be less satisfied with their supervisors, the nature of work and their co-workers than with low psychoticism (tender minded) scores (Camgoz and Karapinar, 2011). Dunn, Mount, Barrick \& Ones (1995) purport emotional stability is the second most important characteristic that affects the employability of candidates. Organization needs employees who are emotionally stable as they will be able to perform to their best. Warr, Cook \& Wall (1979) using a six-item scale to measure anxiety about a variety of current and future concerns, found low but significant negative correlations with various components of their job satisfaction measure.

On the other hand neurotic individuals, who are those who score low on levels of Emotional Stability experience more negative life events (Magnus, Diener, Fujita \& Pavot, 1993). This may be because they put themselves in situations that can foster negative effects (Emmons, Diener \& Larsen, 1985). Neuroticism has been described as the primary source of negative affectivity, and the link between negative affectivity and job satisfaction was documented in Connolly \& Viswesvaran's (2000) meta-analysis, which showed that neuroticism was negatively correlated to job satisfaction. This negative perception can influence, and therefore lower, the perception of satisfaction in the work place. Individuals who are low in Emotional Stability are more likely to be irritable, depressed, or anxious, and these traits inhibit the completion of workplace tasks (Barrick \& Mount, 1991). Thus, low levels of Emotional Stability will lead to decreases in both job satisfaction and job performance because of the negative moods and perceptions that typically occur in emotionally unstable individuals.

The negative effect of Neuroticism makes individuals less able to feel positive experiences and thus show lower satisfaction and lack of positive emotions. For the domain of job satisfaction, Argyle (1989) found that neurotic individuals cannot handle stress well and therefore tend to work inefficiently and suffer from health problems. This leads to a lower job satisfaction, as was found by Judge and llies, (2002). Negative emotionality deals with whether a person adjusts to an unpleasant situation or becomes emotionally unstable. It looks at a person's ability to be rational, resist urges, and use positive coping. Employees with high neuroticism scores tended to be less satisfied with the amount of work, their co-workers and their pay. Therefore, overally, individuals high in neuroticism are less satisfied with their work as compared to those with emotional stability.

\section{Methodology}

A sample of $(n=126)$ employees comprising of males and females, permanent and contract employees members in the selected banks in the Eastern Cape South Africa was used. Statistical analysis involved both descriptive and inferential statistics (SAS 9.1, Pearson's Correlation Coefficient, ANOVA and Waller- Duncan K-ratio T Test and T Test).

\section{Findings}

\subsection{ANOVA and Waller-Duncan K-ratio T Test for Comparisons of Means in Personality and Job Satisfaction for the Different Demographic Features}


Table 1

\begin{tabular}{|c|c|c|c|c|c|}
\hline Variable & DF & F- Value & t Value & Waller Grouping & $\operatorname{Pr}>\mathbf{F}$ \\
\hline Age & 3 & 3.51 & 2.08959 & $(A) A B A B \quad B)-\left(\begin{array}{llll}4 & 2 & 1 & 3\end{array}\right)$ & 0.0174 \\
\hline Race & 3 & 4.42 & 2.00959 & $(A \mathrm{AB} B \mathrm{~B})-\left(\begin{array}{llll}1 & 2 & 4 & 3\end{array}\right)$ & 0.0055 \\
\hline Qualification & 4 & 0.75 & 2.87133 & $(\mathrm{~A} A \mathrm{~A} A \mathrm{~A})-\left(\begin{array}{lllll}5 & 4 & 1 & 2 & 3\end{array}\right)$ & 0.5568 \\
\hline Experience & 4 & 7.15 & 1.89090 & (A AB AB B B)- $(54123)$ & $<.0001$ \\
\hline Bank & 2 & 7.81 & 1.88021 & $(A \mathrm{~A} B)-\left(\begin{array}{lll}2 & 3 & 1\end{array}\right)$ & 0.0006 \\
\hline Job Title & 2 & 15.79 & 1.80420 & $(A \mathrm{~A} B)-\left(\begin{array}{lll}2 & 3 & 1\end{array}\right)$ & $<.0001$ \\
\hline
\end{tabular}

From the mean levels of neuroticism it shows that in all age groups there were low levels of neuroticism with the age group $45+$ having the mean value of (mean=2.5454545), and (mean=1.77702703) for 35-44 age groups. The only significant difference shown was with neuroticism ( $\mathrm{pr}>\mathrm{F}=0.0055, \mathrm{t}=2.00959)$ in the Black and Asian race. The mean level of neuroticism was very low in the Black race (mean= 2.3698630) and even lower in Asians (mean=1.708333). Also a significant relationship was found between race and neuroticism ( $r=-0.29621 ; p=0.0008)$.

Age had a significant difference with neuroticism ( $\mathrm{pr}>\mathrm{F}=0.0001, \mathrm{t}=1.89090)$, those with 20+ years of experience (mean=3.2500000) had a slightly higher neuroticism than those with 11-15 years (mean=1.7763158). A significant negative correlation was also found between banks experience and neuroticism ( $r=-0.24713 ; p=0.0053)$.

The type of bank had a significant difference with neuroticism ( $\mathrm{pr}>\mathrm{F}=0.0006, \mathrm{t}=1.88021)$ where bank 1 (mean=2.532500) had low neuroticism levels and bank 2 (mean=1.7880435) had lower levels of neuroticism. A correlation was also found between banks and neuroticism ( $r=0.18825 ; p=0.0348)$. In terms of job titles there was a great significant difference with all personality traits and job satisfaction Significant relationships were found between neuroticism $(r=0.31769 ;=0.0003)$,

Employees in the management category had low mean levels of neuroticism (mean=2.2820513), whilst consultants had low levels of neuroticism (mean=2.3888889) and Tellers had neuroticism (mean=1.3020833).

\subsection{T Tests for mean differences on gender and job status}

\section{Table 2}

\begin{tabular}{llllllll}
\hline Variable & level & $\mathrm{N}$ & $\mathrm{SD}$ & comparison by & $\mathrm{df}$ & $\mathrm{t}$ value & $\operatorname{Pr}>\mathrm{t}$ \\
\hline \multirow{3}{*}{ Gender } & Male & 53 & 0.7508 & neuroticism & 124 & 1.77 & 0.0786 \\
& Female & 73 & 0.5388 & job satisfaction & 124 & 0.07 & 0.9425 \\
\multirow{5}{*}{ Job Status } & permanent & 116 & 0.6436 & neuroticism & 124 & 0.80 & 0.4240 \\
& Temporary & 10 & 0.3375 & job satisfaction & 124 & 2.33 & 0.0214 \\
\hline
\end{tabular}

In terms of gender there was a significant difference with neuroticism ( $p r>t=0.0318, t=-2.17$ ) though the mean levels are low for neuroticism for both male (mean=1.9433962) and female (mean=2.2979452). A correlation was also found between gender and neuroticism $(r=0.19137 ; p=0.0318)$. Job status had a significant difference with job satisfaction $(p r>t=0.0214, t=2.33)$ and also had a significant relationship $(r=-0.20482 ; p=0.0214)$. There was no significant difference between job status and all the personality traits.

\subsection{Pearson correlation between neuroticism and job satisfaction}

\section{Figure 1}

\begin{tabular}{|c|c|c|}
\hline \multicolumn{3}{|c|}{$\begin{array}{c}\text { Pearson Correlation Coefficients, } \mathbf{N}=126 \\
\text { Prob }>|r| \text { under H0: Rho=0 }\end{array}$} \\
\hline & Neuroticism & job satisfaction \\
\hline Neuroticism & 1.00000 & $\begin{array}{c}0.19084 \\
0.0323\end{array}$ \\
\hline Job_Satisfaction & $\begin{array}{c}0.19084 \\
0.0323\end{array}$ & 1.00000 \\
\hline
\end{tabular}

The statistical analysis with Pearson Correlation significantly indicated that neuroticism was positively and weakly correlated to job satisfaction $(r=0.19084 ; p=0.0323)$. The mean levels of the neuroticism personality trait show that it was very low (mean=2.14881). Hence low neuroticism is positively related to job satisfaction and more likely to be less 
distracted easily, which increases their behavioural risks and suggests a positive relationship between insufficient work efficiency and neuroticism. Correlation between neuroticism and variables of job satisfaction are shown in annexure 1.

\section{Discussion}

$\mathrm{H1}$ : There is a significant relationship between the neuroticism trait and job satisfaction among the bank employees

The statistical analysis with Pearson Correlation significantly indicated that neuroticism was positively and weakly correlated to job satisfaction $(r=0.19084 ; p=0.0323)$. The mean levels of the neuroticism personality trait show that it was very low (mean=2.14881). Hence low neuroticism is positively related to job satisfaction, and less likely to be distracted easily, which has less behavioural risks.

There were significant differences with neuroticism and gender. Though the mean levels were low for neuroticism, the female mean was higher than of male's. These results are consistent with cross cultural research which had showed some patterns of gender difference in response to the big five personality traits. Women consistently report higher neuroticism and men often report higher on extraversion and openness (Costa et al., 2001 Schmitt et al., 2008). Donohue \& Heywood (2004); Oshagbemi (2000) could not prove gender satisfaction differences in a study conducted amongst young American and British employees. There are few, if any studies suggest that gender plays a role in job satisfaction (Brush, Moch \& Pooyan, 1987).

Average levels of Neuroticism generally declined with age but increased slightly starting around age 80 (Terracciano et al., 2005), where neuroticism was low in employees in the range of 35-44 years and 45+ years. This is consistent with the findings of Reudavey (2001) in which it was determined that age and job satisfaction are not related based on a sample of employees in the aviation industry. Lee (1996) also found no relationship between age and job satisfaction.

The only significant difference shown was with neuroticism in the Black and Asian races though it was low. The other significant difference was with job satisfaction which was high on both the Coloured race and White race. A number of studies have also found that White employees amongst different occupational classes experienced higher levels of job satisfaction in comparison to African employees (Friday et al., 2004).

There were no significant differences seen on education qualification and neuroticism. Qualifications had significant differences with job satisfaction were job satisfaction was high in employees with Masters Degrees and slightly high on employees with Certificates. These results are consistent with Bjork et al. (2007) who discovered that nurses with a master's degree or other continuing education were more satisfied than those without additional education. The comparison between job satisfaction and education was also supported by Gazioglu \& Tansel (2002) who observed that those with degrees and postgraduate degree holders had lower levels of job satisfaction compared to individuals with lower levels of education. Considering the highest qualifications experienced job satisfaction can be attributed to increased compensation or position in the organization which comes with the level of education.

There was also a significant difference with neuroticism those with 20+ years of experience had slightly higher neuroticism and those with 11-15 years had low neuroticism. Young employees are still high in openness as there are at a stage where they a creative, full of exploration and more curious than older employees who are now satisfied with their work like as it is.

Job satisfaction had significant difference with job titles as it was high among management employees (mean=4.0833333) than tellers (2.8145833). These results are consistent with Burke (1996) who found that men and women at more senior levels in an organization reported higher levels of job satisfaction in relation to administrative, clerical and secretarial staff. Several other researchers have also found support for a positive association between job level and satisfaction. Results from a study by Robie, Ryan, Schmieder, Parra and Smith (1998) revealed a consistent and significant positive relationship between these two variables.

Form the study it can attributed to most employees in higher positions such as management, are more satisfied with their jobs as they receive more salary and benefits than tellers. Also their jobs give them more flexibility and variety than that of tellers who have routine jobs, which affects job satisfaction.

Job status had a significant difference with job satisfaction and there was no significant difference with all the personality traits. One can comment that the personality and job status of an employee have no significant difference as one may always have the same personality whether; the job was permanent or temporary. Permanent employees were more satisfied as they have job security and continued employment especially when unemployment rates are high in Eastern Cape. Temporary employees scored reasonably on job satisfaction. This finding can be linked to gaining valuable experience to use in the future; hence, they are happy to be given the opportunity. The statistical analysis with 
the Pearson Correlation significantly indicated that neuroticism was positively and weakly related to job satisfaction. Low neuroticism was positively related to job satisfaction; therefore employees who had low neuroticism where satisfied with their jobs.

For a banking career, which requires encounters with a variety of people, countless work phases, haste in work, pressure at work those without good control to cope with emerging unfavorable situations would rarely feel satisfied with their job. Another important aspect is that work in banking requires team work and social relationships. As Asendorpt \& Wilper (1998), Barrick et al., (1998) added successful teamwork must involve persons who possess no aspect of neuroticism which leads to job satisfaction as a whole. As Tokar et al., (1998) noted in their qualitative review, greater job satisfaction is related to lower neuroticism and its variants, as well as to higher extraversion and related traits.

Persons with low levels of Neuroticism tend to be calm and free from persistent negative feelings (Howard \& Howard, 2004). It could be reasoned that, as bank employees were well trained in serving customers they were aware of being calm, relaxed and had good self-emotional control. Several studies (Watson \& Hubbard, 1996; Judge et al., 1998; 2000) have found that neuroticism is negatively correlated with job satisfaction. Consequently, emotional stability is positively correlated with job satisfaction.

According to Mount et al., (1998), service employees such as bank employees scoring high on Emotional Stability (low neuroticism) are likely to be more relaxed and tolerant of stress, which helps them build credibility and trust with clients. Credibility and trust have been linked to higher quality service suggesting that Emotional Stability and service performance are positively correlated.

\section{Conclusion and Recommendations}

Personality is very important in considering candidates for a position. However, it is not enough to serve as a measuring tool for the recruitment process. Personality helps to determine whether an individual is suitable for a particular work environment, such as a liberal work environment requires a liberal person, front-office personnel have to be warm and outgoing not only on a professional level, but on a personal one as well. Personality traits are an important factor and make a difference in job satisfaction, managers can utilize the personality traits questionnaire as a first screening in recruiting. This can be an alternative useful tool in selecting and retaining good employees, in turn, reducing turnover rate and costs associated with employee turnover thereof. Bank management should have motivational strategies to increase the job satisfaction and to retain employees for as long as possible. Management should encourage unique behaviour in order to allow for a culture of continuous learning. Management can also find innovative methods that reduce the chances of neuroticism increasing in the workplace.

The managers need to understand how best to make work more satisfying for staff and to overcome obstacles to effective performance. Globalization has increased competition and in order for continued growth; retains valuable employees; increase competitive advantage; achieve the competitive advantage; organisations must attract and retain employees with balanced personal characteristics.

\section{References}

Argyle, M. (1989): The social psychology of work. (2nd ed.). Harmondsworth: Penguin Group.

Asendorpe, J.B. \& Wilpers, S. (1998). Personality effects on relationships. Journal of Personality and Social Psychology (online).

Barrick, M.R. \& Mount, M.K. (1991). The big five personality dimensions and job performance: A meta-analysis. Personnel Psychology, 44, 1-26.

Bjork, I.T., Samdal, G.B., Hansen, B.S., Torstad, S. \& Hamilton, G.A. (2007). Job satisfaction in a Norwegian population of nurses: A questionnaire survey. International Journal of Nursing Studies, 44, 747-757.

Brush, D. I. I., Moch, M. K. \& Pooyan, A. (1987). Individual demographic differences and job satisfaction. Journal of Occupational Behavior, 8 , 139-155

Buitendach, J.H., \& De Witte, H. (2005). Job insecurity, extrinsic and intrinsic job satisfaction and affective organisational commitment of maintenance workers in a parastatal. South African Journal of Business Management, 36, 27-37.

Camgoz, S. M. \& Karapinar, P. B. (2011). Managing Job Satisfaction: The Mediating Effect of Procedural Fairness. International Journal of Business and Social Science, 2, 234-243.

Connolly, J.J. \& Viswesvaran, C. (2000). The role of affectivity in job satisfaction: A meta-analysis. Personality and Individual Differences, 29 , $265-281$

Costa, P. T. \& McCrae, R. R. (1980). Somatic complaints in males as a function of age and neuroticism: A longitudinal analysis. Journal of Behavioral Medicine, 3, 245-257.

Donohue, S. \& Heywood, J. (2004). Job satisfaction and Gender. An expanded specification from the NLSY. Int. J. Manpower, 25, $211-238$.

Dunn, W.S., Mount, M.K., Barrick, M.R. \& Ones, D.S. (1995). Relative importance of personality and general mental ability in managers' judgments of applicant qualifications. Journal of Applied Psychology, 80, 500-509.

Emmons, R. A., Diener, E., \& Larsen, R. J. (1985). Choice and avoidance of situations and congruence models of interactionism. Personality and 
Individual Differences, 6, 693-702.

Friday, S.S., Moss, S.E. \& Friday, E. (2004). Socioethnic explanations for racioethnic differences in job satisfaction [Electronic version]. The Journal of Management, 23, 152-168.

Gazioglu, S. \& Tansel, A. (2002). Job satisfaction: Work environment and relations with managers in Great Britain. Ankara. Middle-East Technical University.

Goldberg, L. R. (1992). The development of markers for the Big-Five factor structure. Psychological Assessment, 4, $26-42$.

Judge, T.A. \& Cable, D.M. (1997). "Applicant Personality, Organizational Culture, and Organization Attraction." Personnel Psychology, 50, 359394

Judge, T.A. \& llies, R. (2002). Relationship of personality to performance motivation: A meta-analytic review. Journal of Applied Psychology, 87, 797-807.

Lee, R. (1996). Age, education, job tenure, salary, job characteristics, and job satisfaction: A multivariate analysis. Human Relations, 38, 781- 791

Locke, E.A. (1976). The nature and causes of job satisfaction. Handbook of Industrial and Organizational Psychology. Ed. M. D. Dunnette. Chicago, Rand-McNally, 1297-1349.

Magnus, K., Diener, E., Fujita, F. \& Pavot, W. (1993). Extraversion and neuroticism as predictors of objective life events: A longitudinal analysis. Journal of Personality and Social Psychology, 65, 1046-1053.

Mount, M. \& llies, R. (2006) Relationship of personality traits and counterproductive work behaviors: the mediating effects of job satisfaction, Personnel Psychology, 59, $591-622$.

Oshagbemi, T. (2000). Gender differences in the job satisfaction of university students [Electronic version]. Women in Management Review, 15, 331-343.

Reudavey, P. (2001). An examination of job satisfaction and employee motivation of ground crew staff within Ansett, Australia. Working Paper Series, School of Management, Curtin University of Technology.

Robie, C., Ryan, A.M, Schmieder, R.A., Parra, L.F. \& Smith, P.C. (1998). The relation between job level and job satisfaction. Group \& Organisation Management, 23,470-496.

Schmitt, D. P., Realo, A., Voracek, M. \& Allick, J. (2008). Why can't a man be more like a woman? Sex differences in Big Five personality traits across 55 cultures. Journal of Personality and Social Psychology, 94, 168-182.

Sempane, M.E., Rieger, H.S. \& Roodt, H.S. (2002). Job Satisfaction in relation to organisation culture. SA Journal of Industrial Psychology, 28, 23-30

Spector, P. (2008). Industrial and Organisational Behaviour .(5th Ed). New Jersey: JohnWiley \& Sons.

Staw, B. M., \& Ross, J. (1985). Stability in the midst of change: A dispositional approach to job attitudes. Journal of Applied Psychology, $70,469-$ 480.

Terracciano, A., Löckenhoff, C. E., Zonderman, A. B. Ferrucci, L. \& Costa P. T. (2008). Personality Predictors of Longevity: Activity, Emotional Stability, and Conscientiousness. Psychosomatic Medicine, 70, 621-627.

Tokar, D. M., Fischer, A. R. \& Mezydlo Subich, L. (1998). Personality and vocational behavior: A selective review of the literature, 1993-1997. Journal of Vocational Behavior, 53, 115-153.

Warr, P. B., Cook, J .D., \& Wall, T. D. (1979). "Scales for the measurement of some work attitudes and aspects of psychological well-being", Journal of Occupational Psychology, 52, 129-148.

Watson, D. \& Clark, L.A. (1992). On traits and temperament: general and specific factors of emotional experience and their relation to the five factor model. J. Person, 60, 441-475.

Widiger, T \& Trull, T. J. (1992). Personality and Psychopathology: An Application of the Five-Factor Model. Journal of Personality. 60, 363-393.

\section{Annexure 1}

\section{Correlation between personality and variables of job satisfaction}

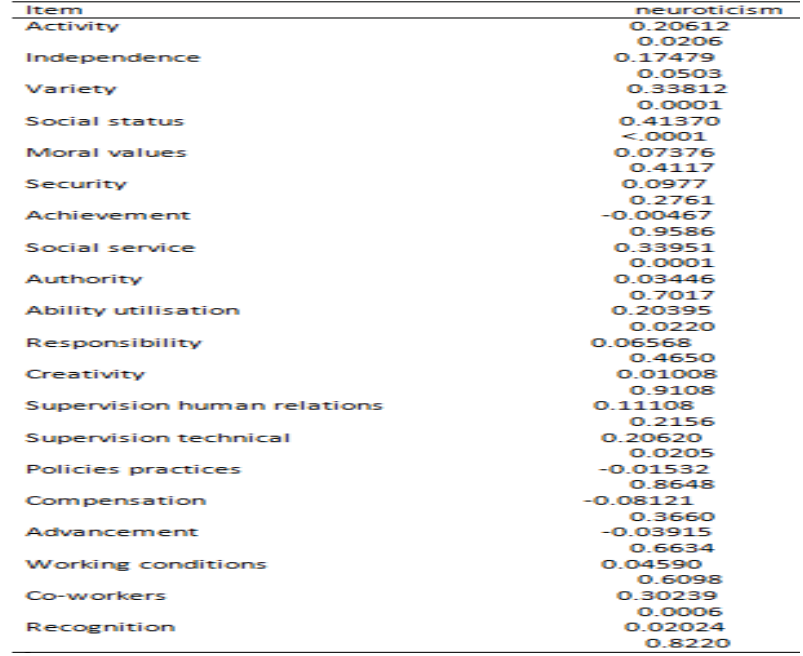

